\title{
Cross-talk between high light stress and plant defence to the two-spotted spider mite in Arabidopsis thaliana
}

\author{
A. K. Barczak-Brzyżek ${ }^{1}$ M. Kiełkiewicz ${ }^{1}$ - P. Gawroński ${ }^{1}$ • \\ K. Kot ${ }^{1} \cdot$ M. Filipecki ${ }^{1} \cdot$ B. Karpińska ${ }^{1,2}$
}

Received: 12 July 2017/Accepted: 1 November 2017/Published online: 8 November 2017

(C) The Author(s) 2017. This article is an open access publication

\begin{abstract}
Little is known about how plants deal with arthropod herbivores under the fluctuating light intensity and spectra which occur in natural environments. Moreover, the role of simultaneous stress such as excess light (EL) in the regulation of plant responses to herbivores is poorly characterized. In the current study, we focused on a mite-herbivore, specifically, the two-spotted spider mite (TSSM), which is one of the major agricultural pests worldwide. Our results showed that TSSM-induced leaf damage (visualized by trypan blue staining) and oviposition rate (measured as daily female fecundity) decreased after EL pre-treatment in wild-type Arabidopsis plants, but the observed responses were not wavelength specific. Thus, we established that EL pre-treatment reduced Arabidopsis susceptibility to TSSM infestation. Due to the fact that a portion of EL energy is dissipated by plants as heat in the mechanism known as non-photochemical quenching (NPQ) of chlorophyll fluorescence, we tested an Arabidopsis npq4-1 mutant impaired in NPQ. We showed that $n p q 4-1$ plants are significantly less susceptible to TSSM feeding activity, and this result was not dependent on light pre-treatment. Therefore, our findings strongly support the role of light in plant defence against TSSM, pointing to a key role for a photoprotective mechanism such as NPQ in this regulation. We hypothesize that plants impaired in NPQ are constantly primed to mite attack, as this seems to be a universal evolutionarily conserved mechanism for herbivores.
\end{abstract}

Keywords Tetranychus urticae Excess light $\cdot$ Biotic and abiotic stress interaction · Non-photochemical quenching (NPQ)

M. Filipecki

marcin_filipecki@sggw.pl

Warsaw University of Life Sciences - SGGW, Warsaw, Poland

2 Centre for Plant Sciences, School of Biology, Faculty of Biological Sciences, University of Leeds, Leeds, UK 


\section{Introduction}

In natural environments, plants are subjected to many simultaneous stresses which result in the activation of various signalling pathways that are integrated into one regulatory network (Koussevitzky et al. 2007; Mittler 2002; Mühlenbock et al. 2008; Trotta et al. 2014). Light is one of the most important environmental factors for plants, as it provides the source of energy for photosynthesis and plays a key role in multiple plant developmental processes (Cerdán and Chory 2003; Jiao et al. 2007; Kaiserli et al. 2015). However, in natural situations plants are exposed to varying light intensities due to the angle of the sun, transient shading by the canopy, and diurnal and seasonal changes in light intensity and quality. During sunny days plants encounter light intensities that often exceed their photosynthetic capacity (Mishra et al. 2012). The sudden exposure of plants to such light episodes may cause a range of light stress effects. Dissipation of excess excitation energy (EEE) in plants is achieved by a combination of so-called non-photochemical (NPQ) and photochemical quenching processes. NPQ dissipates the EEE as heat. This process is caused by the acidification of the chloroplast lumen, and involves a chlorophyll-pigmentbinding protein of the photosystem II (PSII) subunit S protein (PsbS), and other PSassociated proteins (Ciszak et al. 2015; Li et al. 2004; Müller et al. 2001; Niyogi 2000; Niyogi et al. 2005). EEE is ultimately associated with the production of reactive oxygen species (ROS) such as hydrogen peroxide $\left(\mathrm{H}_{2} \mathrm{O}_{2}\right)$, superoxide $\left(\mathrm{O}_{2}^{-}\right)$, and singlet oxygen $\left({ }^{1} \mathrm{O}_{2}\right)$ that can both signal and cause damage. The detoxification of excess ROS relies on antioxidants and antioxidant enzymes (Foyer and Noctor 2005, 2009; Noctor and Foyer 1998). Antioxidants include ascorbate, tocopherols, carotenoids, and anthocyanins (DellaPenna and Pogson 2006; Foyer and Shigeoka 2011). Antioxidant enzymes involve superoxide dismutase (SOD) and ascorbate peroxidase (APX) that disproportionate $\mathrm{O}_{2}$ radicals and catalyse the conversion of $\mathrm{H}_{2} \mathrm{O}_{2}$ to water, respectively (Asada 1999). Acclimation responses to EL episodes are induced within minutes in distal leaves, and the response is proportionally dependent on the quality and quantity of light (Gordon et al. 2013). Light stress induces plant tolerance to pathogen infection as well as to oxidative stress in systemic tissues, indicating a cross-talk between light stress acclimation and pathogen responses (Mühlenbock et al. 2008; Rossel et al. 2007; Szechyńska-Hebda et al. 2010; Zhao et al. 2014). EEE has been shown to induce systemic acquired resistance (SAR) and basal defences to virulent biotrophic bacteria. This response is accompanied by alterations in ROS and redox signals, and the induction of glutathione, salicylic acid (SA), and ethylene (ET) in both local and systemic leaves (Mühlenbock et al. 2008; SzechyńskaHebda et al. 2010). Moreover, it was demonstrated that high-light pre-exposure caused enhanced resistance to aphid infestation in wild-type plants and in mutant lines defective in the composition of B-subunits on the trimeric protein phosphatase 2A (PP2A) holoenzymes (Rasool et al. 2014).

Most of the research on the plant-biotic stress interaction concerns plant defences against different species of pathogens, nematodes, and insect-pests, while the studies on plant defence against mite-pests are limited. The two-spotted spider mite (TSSM) (Tetranychus urticae Koch; Prostigmata: Tetranychidae) is one of the most destructive polyphagous arthropod herbivores, feeding on hundreds of wild and crop plant species. Recently, several transcriptomic approaches allowed to establish molecular basis of its ability to adapt to different host plant species such as Arabidopsis, tomato and grapevine (Grbić et al. 2011; Wybouw et al. 2015; Díaz-Riquelme et al. 2016; Rioja et al. 2017). These thorough analyses often included monitoring of host plant transcriptional dynamics upon TSSM infestation and together with Arabidopsis and tomato focused research 
(Zhurov et al. 2014; Martel et al. 2015), gave an extensive overview on gene expression changes occurred starting from the early time points of infestation. However, there is a lack of data on how plants respond to TSSM in the presence of other stresses such as high light. Increasing evidence indicates that plant response to the combination of biotic and abiotic stresses cannot be considered from the knowledge of the individual stress responses (Dworak et al. 2016; Suzuki et al. 2014). Such evidence strongly supports the idea of a more detailed study with respect a plant's response to simultaneously occurring stresses.

In the present study, using different light quality, we analysed the effect of high light pre-treatment on the plant response to TSSM. To elucidate the involvement of photoprotection mechanisms such as NPQ we used npq4-1 Arabidopsis thaliana mutants. Our study showed that short EL episodes are memorized by plants, which in turn causes a less susceptible response to TSSM. Therefore, our findings broaden the knowledge about how plants function in the natural environment, which forces them to develop optimized responses to combined biotic and abiotic stresses.

\section{Materials and methods}

\section{Plant materials and growth conditions}

All A. thaliana plants used in the experiments were of the Columbia ecotype (Col- 0$)$. The npq4-1 mutant has a deletion in the NPQ4 gene (At1g44575) derived from fast neutron bombardment, and was obtained from the Arabidopsis Biological Resource Center (ABRC, Ohio State University, USA). Over a period of 4 weeks, A. thaliana (Col-0) plants were grown under $8 \mathrm{~h} / 16 \mathrm{~h}$ (light/dark) photoperiod at a low light (LL) intensity of $100 \mu \mathrm{mol}$ photons $\mathrm{m}^{-2} \mathrm{~s}^{-1}$.

\section{Excess light pre-treatment}

Plants were exposed to $2 \mathrm{~h}$ (hours) of excess light using LED light sources (Photon Systems Instruments, Brno, Czech Republic) including white light (HL) of $1500 \mu \mathrm{mol}$ photons $\mathrm{m}^{-2} \mathrm{~s}^{-1}$; blue light (BL; $450 \mathrm{~nm}$ ) of $1500 \mu \mathrm{mol}$ photons $\mathrm{m}^{-2} \mathrm{~s}^{-1}$; and red light (RL; $650 \mathrm{~nm})$ of $2000 \mu \mathrm{mol}$ photons $\mathrm{m}^{-2} \mathrm{~s}^{-1}$.

\section{TSSM mass population rearing and oviposition rate assessment}

The Warsaw TSSM strain originating from Sambucus nigra L. was reared on Phasoleous vulgaris L. cv. Ferrari (PNOS, Ożarów Mazowiecki, Poland) for more than 150 generations. The stock mite colony was kept on bean plants grown in a growth chamber at $16 \mathrm{~h} /$ $8 \mathrm{~h}$ (day/night) photoperiod, temperature $23 \pm 1{ }^{\circ} \mathrm{C}$, and $60 \%$ relative humidity. To synchronize the age of experimental females - at the time when female deutonymphs appeared in the stock colony they were transferred to the detached fresh leaves and males were added. After mating young females were maintained on bean leaves until first eggs were laid. Five-day-old females were used in the 'no-choice' performance assay and leaf damage test on Col-0 and npq4-1 mutant plants. Each experimental plant was infested with 20 females. Females were located in the middle of the rosette and had free choice to feed. After $24 \mathrm{~h}$, the eggs laid on all leaves were counted. Since the initial number of females on Col-0 and npq4-1 mutant plants decreased similarly due to dispersal the TSSM oviposition 
rate was expressed as the average number of eggs $\times$ female $^{-1} \times$ plant $^{-1}$ day $^{-1}$ considering the number of remaining females.

\section{Leaf-damage assessment}

Leaf damage was evaluated using the same Arabidopsis plants. Trypan Blue (TB) staining was performed based on Keogh et al. (1980). Mite-infested leaves were submerged in TB solution $(0.016 \% \mathrm{~TB}, 8 \%$ phenol, $8 \%$ glycerol, $8 \%$ lactic acid, and $65 \%$ ethanol) in a $15 \mathrm{~mL}$ conical polypropylene tube, placed in a boiling water bath at $95{ }^{\circ} \mathrm{C}$ for $2 \mathrm{~min}$. and then left in staining solution overnight at room temperature. Later, leaves were cleared with $6 \mathrm{M}$ chloral hydrate solution diluted in water (Avantor, Poland). Stained leaves were observed and digital images of the leaves were captured by stereo microscope (Leica M165-FC; Leica Microsystems, Wetzlar, Germany). Quantification of mite-induced leaf damage was performed using ImageJ software (Schneider et al. 2012). Firstly, leaf area was outlined, image was binarized and damage area was calculated using measurement tool.

\section{Photosynthetic pigments analysis}

\section{After long HL pre-exposure}

Three-week-old A. thaliana plants growing in the conditions described above were exposed to $800 \mu \mathrm{mol} \mathrm{HL}$ for 1 week. The remainder of the plants were maintained in LL conditions. Three mite-infested leaves collected from mite-infested plants ( 20 females per rosette for $48 \mathrm{~h}$ ) and three respective non-infested (control) leaves from control plants were used to evaluate the contents of chlorophyll a, chlorophyll b, and carotenoids (four biological replicates). All leaves were weighed, ground in liquid nitrogen, after which the photosynthetic pigments were extracted using 95\% ethanol and determined as was described in Lichtenthaler (1987).

\section{After short HL pre-treatment}

Four-week-old A. thaliana plants growing in the conditions described above were treated for $3 \mathrm{~h}$ with HL, BL, or RL. Three mite-infested leaves collected from mite-infested plants (20 females per rosette for $72 \mathrm{~h}$ ) and three respective non-infested (control) leaves from control plants were used to evaluate the contents of chlorophyll a, chlorophyll b, and carotenoids as described above.

\section{Chlorophyll a fluorescence assessment}

Three week-old $A$. thaliana plants growing in the conditions described above were used to analyse chlorophyll a fluorescence parameters. The plants were previously exposed to an excess of HL, RL, or BL (described in the excess light pre-treatment section) and then 20 TSSM females per rosette were placed for $96 \mathrm{~h}$ for plant infestation. Next, the plants were used to determine the chlorophyll a fluorescence measurement. A PAM FluorCam $800 \mathrm{MF}$ PSI device (Photon Systems Instruments) and FluorCam 6.0 Software, supplied by manufacturer were used for analysis. Prior to the measurements, the plants were dark adapted for $30 \mathrm{~min}$ in order to determine $\mathrm{F}_{0}$ and $\mathrm{Fm}$. 


\section{Statistical analysis}

Statistical analysis was performed with R software v.2.13. Tukey's honestly significant difference (HSD) function was used from the R base package.

\section{Results}

\section{TSSM feeding activity and oviposition rate}

To assess how the plant-mite herbivore interaction is modulated in fluctuating light environments we used plants pre-exposed to $2 \mathrm{~h}$ of excess light (EL) treatment with different wavelengths: white light (HL), red light $-650 \mathrm{~nm}$ (RL), and blue light $-450 \mathrm{~nm}$ (BL). To differentiate intact leaf cells and those with mite-disrupted cell membranes we performed TB vital staining which is accumulated only in damaged cells (Fig. 1a). In our study, TSSM feeding activity quantified as the area of damage was less extensive if plants were pre-exposed to EL treatments before mite infestation. Pre-exposure to BL and RL, EL caused a reduction in the level of mite-damaged cells similar to HL (Fig. 1b).

Moreover, we analysed the mite oviposition rate expressed as the average number of eggs female ${ }^{-1}$ plant $^{-1}$ day $^{-1}$, which was reduced if the plants were subjected to EL for all treatments (Fig. 1c). HL pre-exposure resulted in the most significant reduction of mite oviposition. The excess of RL and BL had a similar but less significant effect on mite

a
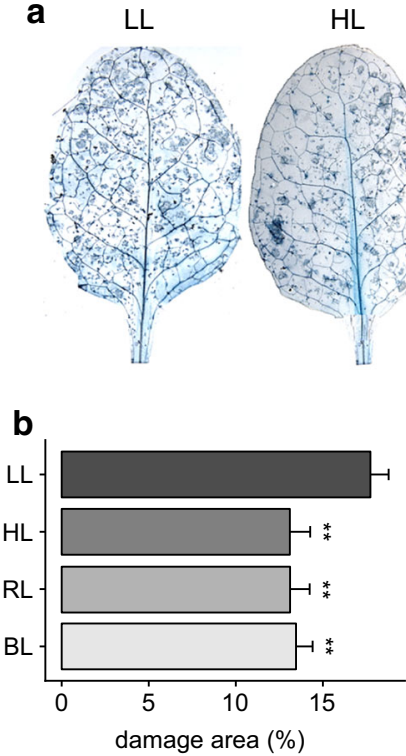

$\mathrm{RL}$
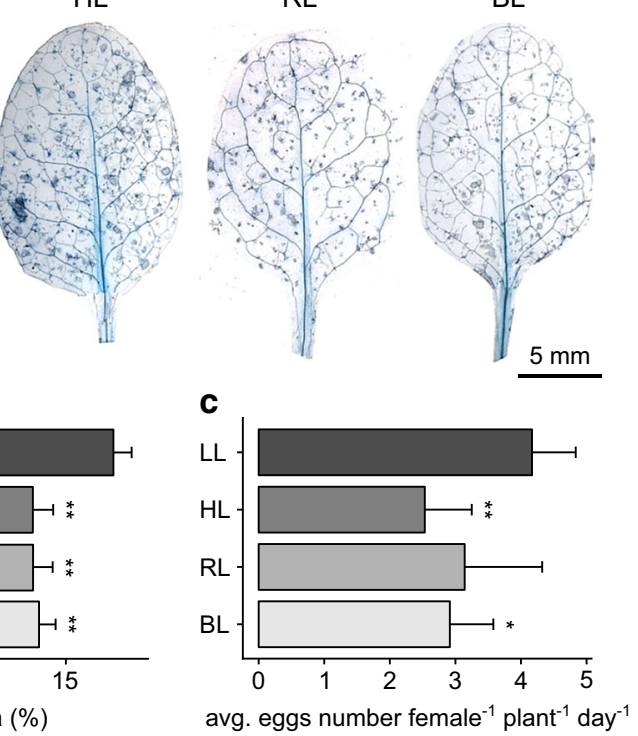

Fig. 1 a Mite-induced leaf damage visualized by TB staining $24 \mathrm{~h}$ post infestation of Arabidopsis thaliana (Col-0) plants. b Extent of damage assessed by the percentage of damaged leaf area $(n=3)$. c TSSM oviposition rate expressed as the average number of eggs female ${ }^{-1}$ plant $^{-1}$ day $^{-1}(n=9)$. LL represents LL-acclimated control plants, and HL, RL, and BL represent plants pre-treated with excess white light, red light, and blue light, respectively. Asterisks indicate significant differences from the LL treatment according to the Tukey HSD test at the level of **0.001, *0.01 
performance. Our results show that EL pre-treatments (HL, RL, BL) decreased susceptibility to TSSM infestation.

\section{The effect of long and short HL pre-exposure on photosynthetic pigments}

In control plants grown under HL conditions for 1 week, the content of chlorophyll a decreased compared to the LL plants. Interestingly, there was no change in the level of this pigment caused by HL treatment when infested plants were analysed (Fig. 2a). HL treatment also resulted in a decline in the chlorophyll b quantity for both control and infested plants. Additionally, we observed a reduction in the total chlorophyll content due to HL treatment, but the differences were mitigated if infested and control plants were compared. For all treatments, the contents of carotenoids were similar and did not change upon HL exposure or TSSM infestation.

Short HL pre-treatment with different light qualities had no effect on the contents of chlorophyll a for the control and infested plants (Fig. 2b). We observed an increase in the chlorophyll b value in infested plants in all HL pre-treated plants, which also translated into changes in the total chlorophyll content, but these changes were not significant. Similarly, for previous experiments we recorded no changes in carotenoids for any of these treatments.
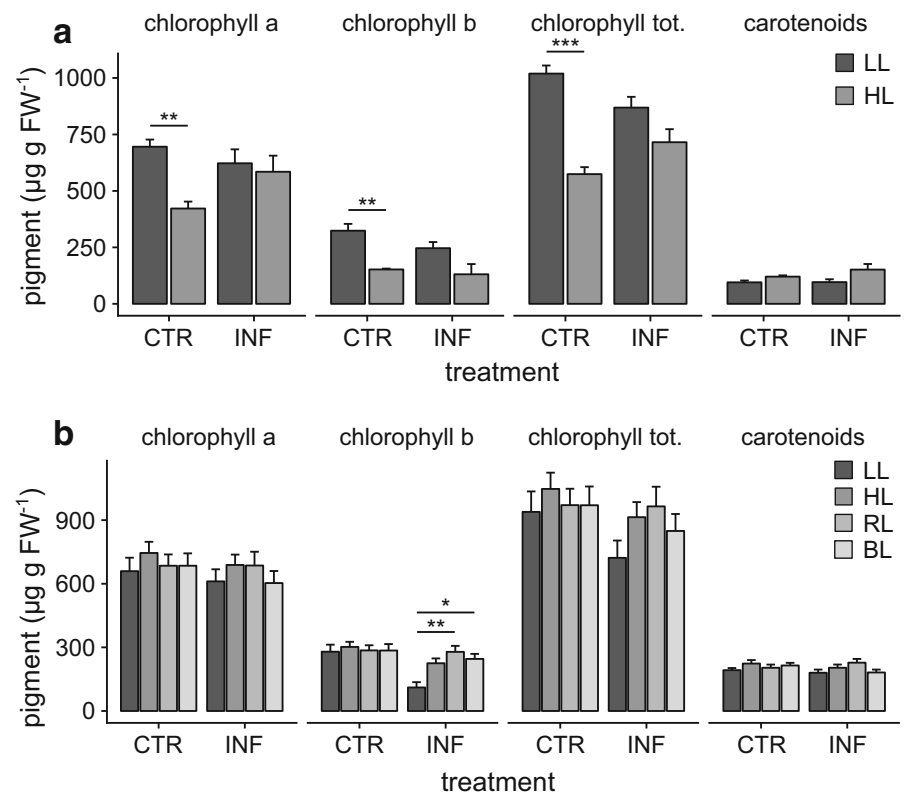

Fig. 2 A comparison of the contents of leaf pigments in non-infested (control; CTR) and TSSM-infested (INF) Arabidopsis thaliana plants for chlorophyll a, chlorophyll b, total chlorophyll, and total carotenoids. a Analyses were performed on plants that had been grown for 3 weeks under low light (LL) and then either maintained for a further week under LL growth conditions, or transferred to high light $\left(800 \mu \mathrm{mol} \mathrm{m}^{-2} \mathrm{~s}^{-1}\right)$ for a subsequent week (HL). b Analyses were performed on plants that had been grown for 4 weeks under low light $\left(100 \mu \mathrm{mol} \mathrm{m} \mathrm{m}^{-2} \mathrm{~s}^{-1}\right)$ and then exposed to $3 \mathrm{~h}$ of EL. LL represents control LL acclimated plants, and HL, RL, and BL represent plants pre-treated with excess white light, red light, and blue light, respectively. Asterisks indicate significant differences according to the Tukey HSD test at the level of $* * * 0.0001, * * 0.001, * 0.01$ 


\section{Chlorophyll a fluorescence quenching parameters}

Chlorophyll a fluorescence quenching parameters were measured on plants exposed for $2 \mathrm{~h}$ to EL (HL, RL, and BL) and then infested with TSSM. Measurements were performed $96 \mathrm{~h}$ post excess light treatment for the control and the infested plants to examine how TSSM infestation affects the activity of the photosynthetic apparatus. No statistically significant differences in the maximum quantum efficiency of PSII (Fv/Fm) were observed for the control and mite-infested plants (Fig. 3). In the control plants the Fv/Fm values were very stable among the replicate measurements, however the infestation caused slight variation, but no visible trend nor statistical significance was noted. Other parameters which we measured included NPQ, which monitors the apparent rate constant for heat loss from PSII (Baker 2008). NPQ increased after TSSM infestation in all cases (Fig. 3), but it was not dependent on previous EL exposures.

\section{The role of NPQ in plant responses to TSSM}

To assess the role of photo-protection mechanisms in the plant response to TSSM, we quantified the area of leaf damage caused by mite feeding activity and performed fecundity assays on $n p q 4-1$ mutant plants lacking the PsbS protein associated with photosystem II (PSII). The area of TSSM caused damage on $n p q 4-1$ leaves was significantly smaller than on the leaves of Col- 0 control plants, and was similar to the wild-type plants pre-treated with HL (Fig. 4a). We observed a similar trend when analysing the mite oviposition rate-npq4-1 mutant plants were less susceptible to TSSM attack, and this result was not affected by EL. Therefore, our results demonstrate that npq4-1 mutant plants are less susceptible to mites, and the EL episodes do not change the plant susceptibility, contrary to wild-type plants.

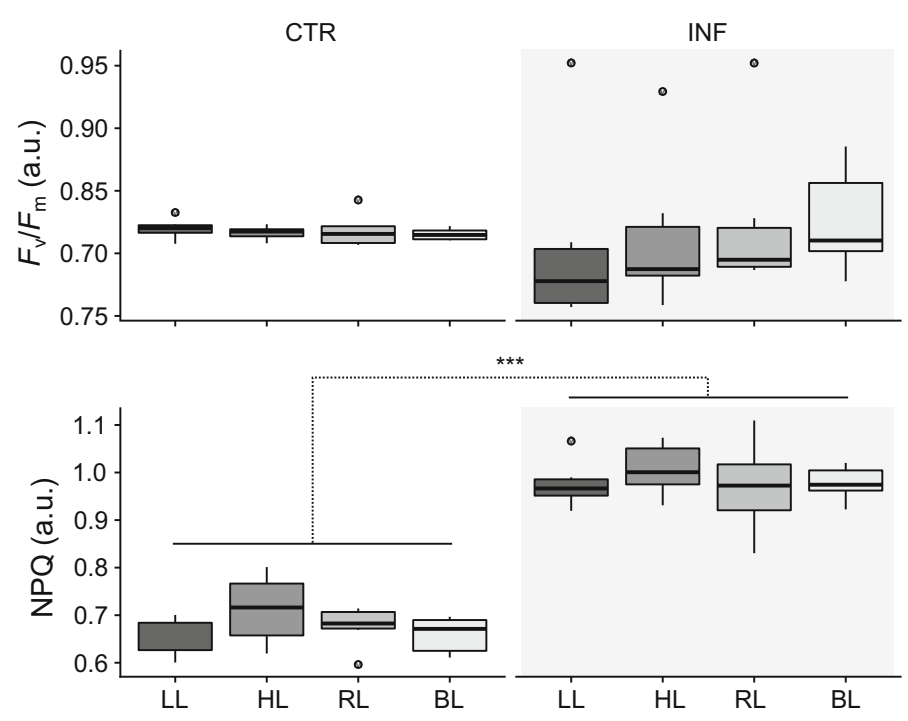

Fig. 3 Photosynthetic parameters of control (CTR) and mite-infested (INF) Arabidopsis thaliana plants. The maximum quantum efficiency of PSII-Fv/Fm and NPQ were examined. (LL) represents LLacclimated plants, whereas (HL), (RL), and (BL) represent plants pre-treated with excess white light, red light, and blue light, respectively $(n=6)$. Asterisks indicate significant differences according to the Tukey HSD test at the level of $* * * 0.0001$ 

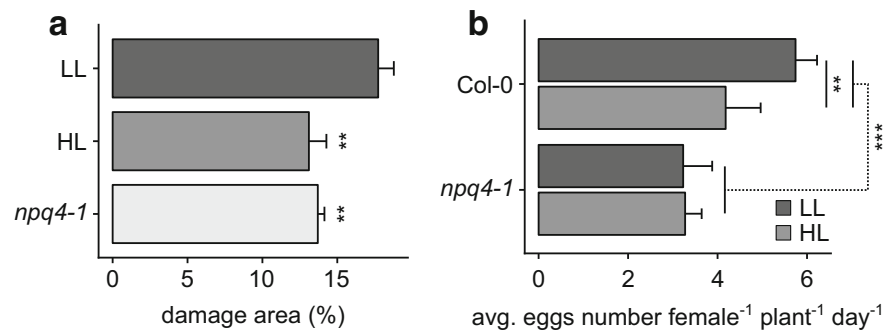

Fig. 4 a Extent of damage assessed by the percentage of damaged Arabidopsis thaliana leaf area for Col-0 and the npq4-1 mutant $(\mathrm{n}=3)$. b TSSM oviposition rate expressed as the average number of eggs female $^{-1}$ plant $^{-1}$ day $^{-1}$ for Col-0 wild-type plants and $n p q 4-1$ mutant plants $(\mathrm{n}=8)$. Asterisks indicate significant differences according to the Tukey HSD test at the level of $* * * 0.0001, * * 0.001$

\section{Discussion}

Light is a main factor which modulates plant growth, development, and yield. Moreover, its excess as well as deficiency has detrimental effects on photosynthesis. In natural conditions optimization of photosynthesis is challenging, because plants cope not only with fluctuating light intensity but its efficiency is an outcome of a plant's response to a combination of biotic and abiotic stresses (Pandey et al. 2015). Therefore, photosynthetic machinery is a fine-tuneable mechanism whose functioning cannot be considered only in the context of plant productivity, as it seems to play a dominant role in the regulation of plant stress resistance (Kangasjärvi et al. 2014; Trotta et al. 2014). Increasing evidence reinforces the profound effect of light on plant resistance/susceptibility to biotic stresses (Göhre et al. 2012; Hua 2013; Rasool et al. 2014; Roden and Ingle 2009; SzechyńskaHebda et al. 2010). This regulation is connected not only with light pre-treatment (Szechyńska-Hebda et al. 2010), but is also dependent on the circadian clock (Bhardwaj et al. 2011; Zhang et al. 2013). It was documented that EL incidents are physiologically memorized by plants, and modulate plant resistance to Pseudomonas syringae (Szechyńska-Hebda et al. 2010) in a wavelength specific manner. Such a mechanism is called light memory, and it is connected with changes in NPQ and membrane potential induced by local EL treatment. Locally induced HL stress is propagated within minutes to systemic leaves by photo-electrochemical signals, such as NPQ and $\mathrm{H}_{2} \mathrm{O}_{2}$, in a phenomenon known as systemic acquired acclimation (SAA) (Karpinski et al. 1999). So far there is limited data concerning the role of light in plant resistance to mite pests. It was documented that light intensity and photoperiod affected glandular trichome density in tomato plants (Nihoul 1993). However, these observations described only plant responses to LL $\left(100 \mu \mathrm{mol}\right.$ photons $\left.\mathrm{m}^{-2} \mathrm{~s}^{-1}\right)$ and shaded $\left(50 \mu \mathrm{mol}\right.$ photons $\left.\mathrm{m}^{-2} \mathrm{~s}^{-1}\right)$ conditions. The density of trichomes which produce exudates increased in plants grown in LL conditions, and caused a rise in mite entrapment by their immobilization. While cited reports point to the reaction of stressed plants, there could be a direct light influence on herbivores. For instance, UVA and UVB radiation have an effect on mite survival, reproduction, and spatial distribution on host-plants (Ohtsuka and Osakabe 2009; Sakai and Osakabe 2010). It was also determined that visible light treatment after UVB treatment caused photoreactivation of adult females, resulting in the increased survival recovery of $T$. urticae and Tyrophagus putrescentiae (Santos 2005), and effects on the egg hatchability of T. urticae as well as predatory mite (Koveos et al. 2017; Murata and Osakabe 2014). 
Here, we described the first evidence of a regulatory role for $\mathrm{HL}$ in the plant response to mite herbivory. Our results showed that in HL pre-treated plants feeding activity was less extensive if we previously exposed plants to light stress. The mite oviposition rate was also significantly lower compared to the control. However, the observed reduction in daily mite fecundity was not dependent on the light quality. Presumably, these light-induced changes are memorized by plants and modulate plant resistance to mites. Therefore, the obtained data confirmed that HL stress can build cross-tolerance to TSSM. On the other hand, if we compare the chlorophyll content in control LL plants and those exposed for HL for 7 days (Fig. 2a) the observed changes in the mite-infested plants were less pronounced. Moreover, in infested plants exposed to short EL episodes (Fig. 2b) the chlorophyll b content increased, a result which was not observed in control plants. Such findings indicate that the plant response to HL could be reversely modulated by subsequent TSSM infestation. Since the fundamental role of light is connected with the regulation of the photosynthesis process, it is not surprising that the photosynthetic machinery is well equipped to protect plants from the harmful effects of the absorption of EEE. NPQ is a mechanism which dissipates excess light energy as heat (Müller et al. 2001; Ware et al. 2015). The fastest and the best described component of NPQ is $\mathrm{qE}$, called energy-dependent quenching, which is induced by the generation of a $\mathrm{pH}$ gradient across the thylakoid membrane (Krause and Behrend 1986; Müller et al. 2001). Acidification of the thylakoid lumen results in the protonation of amino acid residues of the PsbS protein, a crucial component of NPQ, which allows the control of conformational changes in the antenna of PSII (Li et al. 2000, 2004; Niyogi et al. 2005). Mutants impaired in NPQ, lacking PsbS, pigment binding protein (npq4-1), as well as violaxanthin de-epoxidase [which takes part in the xanthophyll cycle (vdel)], and the double mutant npq4vdel, showed an altered flg22 response, which suggests that NPQ modulates PAMP-triggered immunity (PTI) (Göhre et al. 2012). It included enhancement of ROS production in mutant and double mutant plants, as well as an increase in the expression of WRKY22 and WRKY29 in npq4vde1 plants. On the other hand, the levels of photosynthetic proteins change upon flg22 treatment including a decrease in the PsbS level, with a simultaneous decline in NPQ. This parameter reaches a minimum at 1 and $2 \mathrm{~h}$ in the early perception of PAMPs, but then recovers. Prolonged time of exposure to flg22 lead to an increase in NPQ, but a decrease in energy use for photosynthesis. Thus, NPQ may modulate the PTI, but the converse effect of regulation of NPQ by the perception of PAMPs was also observed. Additionally, PsbS-deficient rice showed enhanced resistance to the fungal pathogen Magnaporthe oryzae PO6-6 and the bacterial pathogen Xanthomonas oryzae pv. oryzae (Zulfugarov et al. 2016). The attractiveness of a plant to grazing herbivory (netted slug; Deroceras reticulatum) was also affected by NPQ efficiency, and was lower for the npq4-1 mutant compared to wild-type plants (Frenkel et al. 2009). The observed response is connected with altered levels of JA in plants growing in field conditions and subjected to grazing, which caused an increase in the JA levels in the npq4-1 mutant in comparison to wild-type plants. Finally, insect herbivores (Plutella xylostella and Spodoptera littoralis) feed preferably on PsbS overexpressing (oePsbS) plants. Interestingly, there were no significant differences between $n p q 4-1$, oePsbS, and wild-type plants in the level of glucosinolates, which are key secondary metabolites in the plant-herbivore defence response (Johansson Jänkänpää et al. 2013). Thus, it was postulated that these preferences may result from differences in the primary metabolites, including a modified amino acid pool and reduced sucrose content.

We observed that $A$. thaliana plants lacking PsbS are less susceptible to TSSM, and this result was not affected by light pre-treatment. Therefore, our findings strongly support the idea that plants impaired in NPQ are primed to TSSM attack. It seems to be a general 
mechanism which is universal for herbivorous arthropods with different types of feeding, or for fungal and bacterial pathogens, but the molecular basis of this phenomenon is still unclear. On the other hand, modulation of NPQ by PsbS overexpression increases carbon gain and water-use efficiency, and resulted in 15\% improvement in crop yield (Kromdijk et al. 2016). Thus, PsbS inversely regulates plant biomass production and susceptibility to herbivore attack. Plant exposure to HL causes a reduction in the photosynthetic electron transport chain components, and overproduction of ROS in the chloroplast, cytoplasm, and apoplast (Karpiński et al. 2013). Such imbalances in the photosynthetic apparatus promote the formation of not only ROS but also induce an array of defence related genes.

This paper is an attempt to answer how plants adjust their response, which ensures their survival in a highly changeable environment. The results of this study and earlier observations clearly show that photosynthesis and the photosynthetic machinery influence the plant defence response. We show not only the effect of light on plant susceptibility to TSSM, but also the regulatory role of photo-protective mechanisms such as NPQ in this regulation. We hypothesize that plants impaired in NPQ are constantly primed to mite attack, and this seems to be a universal mechanism for herbivores with different types of feeding, as well as for fungal and bacterial pathogens. Our research strongly supports the idea that it may be an evolutionarily conserved trade-off mechanism between photoprotection and the biotic stress response.

Acknowledgements This study was supported by funding from FP7 Research Potential of Convergence Regions (Grant No. REGPOT-2011-1-286093-WULS-Plant Health) and the POKL.04.03.00-00-042/12-00 programme co-financed by the European Social Fund (to A.B.B).

Author contributions AB-B carried out the experiments and wrote the manuscript. PG was responsible for data analysis and preparation of the figures. KK performed TB staining documentation. BK and MK designed the experiments and equally contributed to this work. MF analysed data and prepared the final version of the manuscript.

\section{Compliance with ethical standards}

Conflict of interest The authors declare that they have no conflict of interest.

Open Access This article is distributed under the terms of the Creative Commons Attribution 4.0 International License (http://creativecommons.org/licenses/by/4.0/), which permits unrestricted use, distribution, and reproduction in any medium, provided you give appropriate credit to the original author(s) and the source, provide a link to the Creative Commons license, and indicate if changes were made.

\section{References}

Asada K (1999) The water-water cycle in chloroplasts: scavenging of active oxygens and dissipation of excess photons. Annu Rev Plant Physiol Plant Mol Biol 50:601-639

Baker NR (2008) Chlorophyll fluorescence: a probe of photosynthesis in vivo. Annu Rev Plant Biol 59:89-113

Bhardwaj V, Meier S, Petersen LN, Ingle RA, Roden LC (2011) Defence responses of Arabidopsis thaliana to infection by Pseudomonas syringae are regulated by the circadian clock. PLoS ONE 6:e26968

Cerdán PD, Chory J (2003) Regulation of flowering time by light quality. Nature 423:881-885

Ciszak K, Kulasek M, Barczak A, Grzelak J, Maćkowski S, Karpiński S (2015) PsbS is required for systemic acquired acclimation and post-excess-light-stress optimization of chlorophyll fluorescence decay times in Arabidopsis. Plant Signal Behav 10:e982018

DellaPenna D, Pogson BJ (2006) Vitamin synthesis in plants: tocopherols and carotenoids. Annu Rev Plant Biol 57:711-738

Díaz-Riquelme J, Zhurov V, Rioja C, Pérez-Moreno I, Torres-Pérez R, Grimplet J, Carbonell-Bejerano P, Bajda S, Van Leeuwen T, Martínez-Zapater JM et al (2016) Comparative genome-wide transcriptome 
analysis of Vitis vinifera responses to adapted and non-adapted strains of two-spotted spider mite, Tetranyhus urticae. BMC Genomics 17:74

Dworak A, Nykiel M, Walczak B, Miazek A, Szworst-Łupina D, Zagdańska B, Kiełkiewicz M (2016) Maize proteomic responses to separate or overlapping soil drought and two-spotted spider mite stresses. Planta 244:939-960

Foyer CH, Noctor G (2005) Oxidant and antioxidant signalling in plants: a re-evaluation of the concept of oxidative stress in a physiological context. Plant Cell Environ 28:1056-1071

Foyer CH, Noctor G (2009) Redox regulation in photosynthetic organisms: signaling, acclimation, and practical implications. Antioxid Redox Signal 11:861-905

Foyer $\mathrm{CH}$, Shigeoka S (2011) Understanding oxidative stress and antioxidant functions to enhance photosynthesis. Plant Physiol 155:93-100

Frenkel M, Külheim C, Jänkänpää HJ, Skogström O, Dall'Osto L, Ågren J, Bassi R, Moritz T, Moen J, Jansson S (2009) Improper excess light energy dissipation in Arabidopsis results in a metabolic reprogramming. BMC Plant Biol 9:12

Göhre V, Jones AME, Sklenář J, Robatzek S, Weber APM (2012) Molecular crosstalk between PAMPtriggered immunity and photosynthesis. Mol Plant Microbe Interact 25:1083-1092

Gordon MJ, Carmody ME, Albrecht V, Pogson B (2013) Systemic and local responses to repeated HL stress-induced retrograde signaling in Arabidopsis. Front Plant Sci 3:303

Grbić M, Van Leeuwen T, Clark RM, Rombauts S, Rouzé P, Grbić V, Osborne EJ, Dermauw W, Ngoc PC, Ortego F, Hernández-Crespo P, Diaz I, Martinez M, Navajas M, Sucena É, Magalhães S, Nagy L, Pace RM, Djuranović S, Smagghe G, Iga M, Christiaens O, Veenstra JA, Ewer J, Villalobos RM, Hutter JL, Hudson SD, Velez M, Yi SV, Zeng J, Pires-daSilva A, Roch F, Cazaux M, Navarro M, Zhurov V, Acevedo G, Bjelica A, Fawcett JA, Bonnet E, Martens C, Baele G, Wissler L, Sanchez-Rodriguez A, Tirry L, Blais C, Demeestere K, Henz SR, Gregory TR, Mathieu J, Verdon L, Farinelli L, Schmutz J, Lindquist E, Feyereisen R, Van de Peer Y (2011) The genome of Tetranychus urticae reveals herbivorous pest adaptations. Nature 479(7374):487-492

Hua J (2013) Modulation of plant immunity by light, circadian rhythm, and temperature. Curr Opin Plant Biol 16:406-413

Jiao Y, Lau OS, Deng XW (2007) Light-regulated transcriptional networks in higher plants. Nat Rev Genet 8:217-230

Johansson Jänkänpää H, Frenkel M, Zulfugarov I, Reichelt M, Krieger-Liszkay A, Mishra Y, Gershenzon J, Moen J, Lee C-H, Jansson S (2013) Non-photochemical quenching capacity in Arabidopsis thaliana affects herbivore behaviour. PLoS ONE 8(1):e53232

Kaiserli E, Paldi K, O’Donnell L, Batalov O, Pedmale UV, Nusinow DA, Kay SA, Chory J (2015) Integration of light and photoperiodic signaling in transcriptional nuclear foci. Dev Cell 35:311-321

Kangasjärvi S, Tikkanen M, Durian G, Aro E-M (2014) Photosynthetic light reactions—an adjustable hub in basic production and plant immunity signaling. Plant Physiol Biochem 81:128-134

Karpinski S, Reynolds H, Karpinska B, Wingsle G, Creissen G, Mullineaux P (1999) Systemic signaling and acclimation in response to excess excitation energy in Arabidopsis. Science 284:654-657

Karpiński S, Szechyńska-Hebda M, Wituszyńska W, Burdiak P (2013) Light acclimation, retrograde signalling, cell death and immune defences in plants. Plant Cell Environ 36:736-744

Keogh RC, Deverall BJ, Mcleod S (1980) Comparison of histological and physiological responses to Phakopsora pachyrhizi in resistant and susceptible soybean. Trans Br Mycol Soc 74(2):329-333

Koussevitzky S, Nott A, Mockler TC, Hong F, Sachetto-Martins G, Surpin M, Lim J, Mittler R, Chory J (2007) Signals from chloroplasts converge to regulate nuclear gene expression. Science 316:715-719

Koveos DS, Suzuki T, Terzidou A, Kokkari A, Floros G, Damos P, Kouloussis NA (2017) Egg hatching response to a range of ultraviolet-B (UV-B) radiation doses for four predatory mites and the herbivorous spider mite Tetranychus urticae. Exp Appl Acarol 71:35-46

Krause GH, Behrend U (1986) $\Delta \mathrm{pH}$-dependent chlorophyll fluorescence quenching indicating a mechanism of protection against photoinhibition of chloroplasts. FEBS Lett 200:298-302

Kromdijk J, Głowacka K, Leonelli L, Gabilly ST, Iwai M, Niyogi KK, Long SP (2016) Improving photosynthesis and crop productivity by accelerating recovery from photoprotection. Science 354(6314):857-861

Li XP, Björkman O, Shih C, Grossman AR, Rosenquist M, Jansson S, Niyogi KK (2000) A pigment-binding protein essential for regulation of photosynthetic light harvesting. Nature 403:391-395

Li X-P, Gilmore AM, Caffarri S, Bassi R, Golan T, Kramer D, Niyogi KK (2004) Regulation of photosynthetic light harvesting involves intrathylakoid lumen $\mathrm{pH}$ sensing by the PsbS protein. J Biol Chem 279:22866-22874

Lichtenthaler HK (1987) [34] Chlorophylls and carotenoids: pigments of photosynthetic biomembranes. Methods Enzymol 148:350-382 
Martel C, Zhurov V, Navarro M, Martinez M, Cazaux M, Auger P, Migeon A, Santamaria ME, Wybouw N, Diaz I et al (2015) Tomato whole genome transcriptional response to Tetranychus urticae identifies divergence of spider mite-induced responses between tomato and Arabidopsis. Mol Plant Microbe Interact 28:343-361

Mishra Y, Jänkänpää HJ, Kiss AZ, Funk C, Schröder WP, Jansson S (2012) Arabidopsis plants grown in the field and climate chambers significantly differ in leaf morphology and photosystem components. BMC Plant Biol 12:6

Mittler R (2002) Oxidative stress, antioxidants and stress tolerance. Trends Plant Sci 7:405-410

Mühlenbock P, Szechyńska-Hebda M, Płaszczyca M, Baudo M, Mateo A, Mullineaux PM, Parker JE, Karpińska B, Karpiński S (2008) Chloroplast signaling and Lesion Simulating Disease1 regulate crosstalk between light acclimation and immunity in Arabidopsis. Plant Cell 20:2339-2356

Müller P, Li X-P, Niyogi KK (2001) Non-photochemical quenching. a response to excess light energy. Plant Physiol 125:1558-1566

Murata Y, Osakabe M (2014) Factors affecting photoreactivation in UVB-irradiated herbivorous spider mite (Tetranychus urticae). Exp Appl Acarol 63:253-265

Nihoul P (1993) Do light intensity, temperature and photoperiod affect the entrapment of mites on glandular hairs of cultivated tomatoes? Exp Appl Acarol 17:709-718

Niyogi KK (2000) Safety valves for photosynthesis. Curr Opin Plant Biol 3:455-460

Niyogi KK, Li X-P, Rosenberg V, Jung H-S (2005) Is PsbS the site of non-photochemical quenching in photosynthesis? J Exp Bot 56:375-382

Noctor G, Foyer CH (1998) Ascorbate and glutathione: keeping active oxygen under control. Annu Rev Plant Physiol Plant Mol Biol 49:249-279

Ohtsuka K, Osakabe MMH (2009) Deleterious effects of UV-B radiation on herbivorous spider mites: they can avoid it by remaining on lower leaf surfaces. Environ Entomol 38:920-929

Pandey P, Ramegowda V, Senthil-Kumar M (2015) Shared and unique responses of plants to multiple individual stresses and stress combinations: physiological and molecular mechanisms. Front Plant Sci $6: 723$

Rasool B, Karpinska B, Konert G, Durian G, Denessiouk K, Kangasjärvi S, Foyer CH (2014) Effects of light and the regulatory B-subunit composition of protein phosphatase 2A on the susceptibility of Arabidopsis thaliana to aphid (Myzus persicae) infestation. Front Plant Sci 5:405

Rioja C, Zhurov V, Bruinsma K, Grbic M, Grbic V (2017) Plant-herbivore interactions: a case of an extreme generalist, the two-spotted spider mite, Tetranychus urticae. Mol Plant Microbe Interact. https: Ildoi. org \10.1094/MPMI-07-17-0168-CR

Roden LC, Ingle RA (2009) Lights, rhythms, infection: the role of light and the circadian clock in determining the outcome of plant-pathogen interactions. Plant Cell 21:2546-2552

Rossel JB, Wilson PB, Hussain D, Woo NS, Gordon MJ, Mewett OP, Howell KA, Whelan J, Kazan K, Pogson BJ (2007) Systemic and intracellular responses to photooxidative stress in Arabidopsis. Plant Cell 19:4091-4110

Sakai Y, Osakabe M (2010) Spectrum-specific damage and solar ultraviolet radiation avoidance in the twospotted spider mite. Photochem Photobiol 86:925-932

Santos CD (2005) Photoreactivation of ultraviolet-B damage in Tyrophagus putrescentiae (Acari: Acaridae) and Tetranychus urticae (Acari: Tetranychidae). Int J Acarol 31:429-431

Schneider CA, Rasband WS, Eliceiri KW (2012) NIH Image to ImageJ: 25 years of image analysis. Nat Methods 9:671-675

Suzuki N, Rivero RM, Shulaev V, Blumwald E, Mittler R (2014) Abiotic and biotic stress combinations. New Phytol 203:32-43

Szechyńska-Hebda M, Kruk J, Górecka M, Karpińska B, Karpiński S (2010) Evidence for light wavelengthspecific photoelectrophysiological signaling and memory of excess light episodes in Arabidopsis. Plant Cell 22:2201-2218

Trotta A, Rahikainen M, Konert G, Finazzi G, Kangasjärvi S (2014) Signalling crosstalk in light stress and immune reactions in plants. Philos Trans R Soc Lond B Biol Sci 369:20130235

Ware MA, Belgio E, Ruban AV (2015) Comparison of the protective effectiveness of NPQ in Arabidopsis plants deficient in PsbS protein and zeaxanthin. J Exp Bot 66:1259-1270

Wybouw N, Zhurov V, Martel C, Bruinsma KA, Hendrickx F, Grbić V, Van Leeuwen T (2015) Adaptation of a polyphagous herbivore to a novel host plant extensively shapes the transcriptome of herbivore and host. Mol Ecol 24:4647-4663

Zhang C, Xie Q, Anderson RG, Ng G, Seitz NC, Peterson T, McClung CR, McDowell JM, Kong D, Kwak JM et al (2013) Crosstalk between the circadian clock and innate immunity in Arabidopsis. PLoS Pathog 9:e1003370 
Zhao Y, Zhou J, Xing D (2014) Phytochrome B-mediated activation of lipoxygenase modulates an excess red light-induced defence response in Arabidopsis. J Exp Bot 65:4907-4918

Zhurov V, Navarro M, Bruinsma KA, Arbona V, Santamaria ME, Cazaux M, Wybouw N, Osborne EJ, Ens C, Rioja C et al (2014) Reciprocal responses in the interaction between Arabidopsis and the cellcontent-feeding chelicerate herbivore spider mite. Plant Physiol 164:384-399

Zulfugarov IS, Tovuu A, Kim C-Y, Vo KTX, Ko SY, Hall M, Seok H-Y, Kim Y-K, Skogstrom O, Moon $\mathrm{Y}-\mathrm{H}$ et al (2016) Enhanced resistance of PsbS-deficient rice (Oryza sativa L.) to fungal and bacterial pathogens. J Plant Biol 59:616-626 